\title{
Design em paralaxe: uma discussão sobre a coexistência de diferentes abordagens do design na contemporaneidade
}

Design in parallax: a discussion on the coexistence of different contemporary design approaches

http://dx.doi.org/10.5007/2178-4582.2016v50n2p548

\author{
Patrícia Wielewicki \\ Universidade do Porto, Porto, Portugal \\ Rui Miguel Ferreira Roda \\ Politecnico di Milano, Milano, Italia
}

\begin{abstract}
Com base na polêmica obra Design and Crime: and other diatribes, de Hal Foster, que aponta o design como um instrumento de modulação cultural e agente promotor de consumo, este trabalho estabelece um debate entre teóricos do campo do design e de outras áreas do saber buscando discutir o "crime do design" sugerido pelo autor. Por meio de revisão de literatura, são abordados os temas: identidade, valor e função no design; e propõe-se o 'design em paralaxe' como um conceito capaz de contribuir para a reflexão sobre as recorrentes caracterizações estereotipadas do design. As conclusões apontam para a necessidade de aprofundamento da reflexão sobre a posição do design frente ao cenário complexo e paradoxal da contemporaneidade, e sinalizam a coexistência de diferentes abordagens do design, assumido neste trabalho como um campo de atuação multifacetado com contornos pouco nítidos.
\end{abstract}

Palavras-chave: Design and Crime; Hal Foster; Design em paralaxe; Estereótipos do design; Diferentes abordagens do design.
With basis on the Hal Foster's polemic work 'Design and Crime: and other diatribes', approaching design as a cultural modulation tool and consumption promoting agent, this study establishes a debate among theoreticians in the area of design and other knowledge areas in order to discuss the "design crime" suggested by the author. By means of a review of literature, the concepts of identity, value and role of design are addressed and the use of 'design in parallax' is proposed as a concept, which may contribute for reflecting the stereotyped recurrent features of design. Conclusions point to the need for deepening reflection on the place of design within the complex and paradoxal contemporary scenery and signal the coexistence of different design approaches, assumed in this work as a multifaceted field of action with blurred contours.

Keywords: Design and Crime; Hal Foster; Design in parallax; Design stereotype; Different design approaches.

\section{Introdução}

Entende-se que um dos grandes paradoxos da contemporaneidade resida no conflito entre o indivíduo e o cidadão. Segundo o sociólogo Zygmunt Bauman (2001), cidadão, como variável dependente da cidadania, é aquele que busca satisfazer os seus desejos e necessidades, porém considera o bem comum ou coletivo em suas ações. Já o indivíduo procura o seu próprio bem acima dos interesses da sociedade. Este conflito manifesta-se internamente em cada pessoa, mas também na sociedade, entre grupos e instituições com diferentes interesses. Assim, assume-se o paradoxo como um sintoma da so- 
ciedade atual, caracterizado por conflitos individuais e coletivos, referentes principalmente à neofilia e à ânsia pelo consumo, e também à busca do equilíbrio ambiental e social.

Complementarmente Victor Margolin (1996), professor e coeditor do jornal acadêmico Design Issues, apresenta sua teoria sobre o 'modelo de equilíbrio para o mundo' e o 'modelo de expansão mundial'. Segundo o autor, o 'modelo de equilíbrio' define o mundo como um ecossistema de equilíbrio delicado, baseado em recursos finitos. Segundo Margolin (2014), pouco a pouco este modelo vem ganhando amplo apoio da sociedade como uma meta a ser objetivada. Já no 'modelo de expansão', alimentado pela ordem e ambição capitalista, orientado a uma fração de consumidores e pelo meio empresarial internacional, o mundo é constituído por mercados em vez de nações, sociedades e culturas, onde os produtos desempenham o papel de agentes do intercâmbio econômico. As diferenças de desenvolvimento social previstas entre os dois modelos não estão apenas em conflito, segundo Margolin (1996), mas em rota de colisão, uma vez que os partidários do modelo equilibrista invocam de forma pouco realista a redução radical do consumo, enquanto os expansionistas apresentam pouco interesse com as questões de ordem ambiental e social.

Os valores conflitantes desses dois modelos apresentam relação direta com o posicionamento do design como disciplina, à medida que discutem os rumos dos modelos de desenvolvimento econômico e social, e abordam temas como: consumo, inovação e sustentabilidade. Dentro deste contexto, segundo Margolin (1996), diante da dificuldade do 'modelo de equilíbrio' de acomodar o crescimento dinâmico da produção e do comércio internacional, a inovação e o desenvolvimento de produtos despontam como a grande força motriz da economia global. Sob esta ótica, o próprio entendimento do que seja inovação exige uma reflexão aprofundada do ponto de vista do design, culminando em questionamentos como: a inovação pode ser trabalhada para além do 'modelo de expansão mundial'? O foco da inovação deve ser o indivíduo ou o cidadão? É possível operar no campo do design conciliando os interesses de ambos? É possível falarmos em um modelo de design e inovação voltado ao indivíduo e ao modelo de expansão, e outro, voltado ao cidadão e ao modelo de equilíbrio?

Sem a pretensão de esgotar os questionamentos apresentados, este texto dialoga com os dois primeiros capítulos do livro 'Design and Crime: and other diatribes' de Hal Foster, crítico e historiador de arte norte americano. Ambiciona-se criar uma espécie de debate tendo com eixo principal as ideias de Foster (2002) de maneira a contribuir para a elucidação da posição do design frente à crise cultural apontada pelo autor, e também ao cenário paradoxal da contemporaneidade apontado por Bauman (2001) e Margolin (1996). 
Lançada em 2002, a polêmica obra Design and Crime: and other diatribes reúne textos escritos entre 1996 e 2001 e dedica-se principalmente à análise de mudanças recentes no status cultural da arquitetura e do design, bem como da arte e crítica no Ocidente. Fortemente dotado de um discurso político, o texto de Foster (2002) critica o atual modelo de consumo, discute a relação entre identidade, cultura, valores, e a participação do design no que o autor chama de modulação cultural. Buscando apontar possibilidades críticas e promover a predileção por alternativas, Foster (2002) sinaliza a existência de uma crise cultural e levanta questões como: até que ponto o sujeito construído do pósmodernismo se tornou o sujeito projetado do consumismo? Até que ponto o campo expandido da arte pós-guerra se tornou um espaço administrado pelo design contemporâneo?

Nesse sentido, na tentativa de elucidação do crime do design sugerido por Foster (2002), explora-se no texto os conceitos de identidade, valor e função no design e na arte, e propõem-se o emprego do conceito 'design em paralaxe', melhor descrito na sequência, como um elemento capaz de contribuir para a reflexão sobre as recorrentes caracterizações estereotipadas do design.

\section{Em busca do "crime do design"}

Em Design and Crime: and other diatribes Hal Foster (2002) defende que tudo aquilo que pode ser construído, pode ser considerado design e designed, desde roupas, personalidades, exposições artísticas, edifícios, corpos ou mesmo os genes humanos. Na opinião do autor o crime do design reside justamente na ambição de construir sujeitos e colonizar a vida cotidiana. Em outras palavras, para Foster (2002) o design é uma espécie de crime estético da sociedade contemporânea norteada pela imagem e pelo novo. De acordo com este pensamento, devido à influência do design na sociedade contemporânea tudo parece ser artificial e superficial, incluindo a própria identidade das pessoas que é, muitas vezes, expressa por marcas comerciais. Tais construções estendem-se para o que Foster (2002) chama de uma elite cultural, onde o status social relaciona-se com as preferências dos indivíduos, culminando na fabricação de perfis socialmente valorizados.

Sob esta perspectiva, a palavra design assume uma posição central na discussão sobre identidade, valores e cultura. Assim, sem a intenção de estabelecer uma definição única do que seja design, julga-se relevante refletir sobre as possíveis associações feitas à esta prática.

Em O mundo codificado: Por uma filosofia do design e da comunicação, Vilém Flusser (2007) ressalta que em inglês, a palavra design pode ser entendida como substantivo e como verbo: 
Como substantivo significa "propósito", "plano", "intenção", "meta", "esquema maligno", "conspiração", "forma", "estrutura básica", termos geralmente relacionados à "astúcia" e à "fraude". Como verbo - to design - significa, entre outras coisas, "tramar algo", "simular", "projetar", "esquematizar", "configurar", "proceder de modo estratégico" (FLUSSER, 2007, p. 181).

Complementarmente ao raciocínio de Flusser, Michel de Certeau (1994, p. 99) define estratégia: "Chamo de estratégia o cálculo (ou manipulação) das relações de forças que se torna possível a partir do momento em que um sujeito de querer e poder (uma empresa, um exército, uma cidade, uma instituição científica) pode ser isolado". E completa ainda se referindo à definição de estratégia: "Gesto cartesiano, quem sabe. Circunscrever um próprio num mundo enfeitiçado pelos poderes invisíveis do Outro. Gesto da modernidade científica, política ou militar" (CERTEAU, 1994, p. 99).

Coincidindo com o perfil simulador apontado por Foster (2002), o design no sentido lato, segundo Flusser (2007), ocorre em um contexto de astúcias e fraudes, e pode ser entendido como uma atividade que conspira a favor de um mundo artificial. Entretanto, de acordo com Flusser (2007), o caráter conspirador e colonizador estende-se a todos os campos do saber culturalmente circunscritos (incluindo a arte e o design).

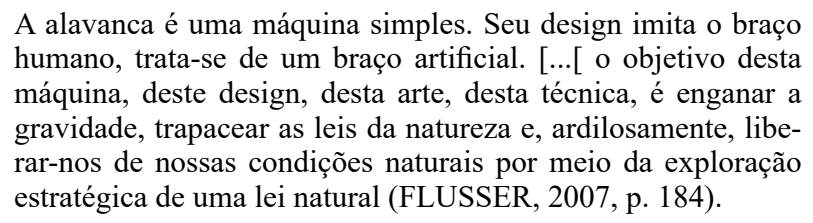

Flusser (2007) e Foster (2002) aparentemente concordam que o designer é um manipulador. A grande diferença entre as duas linhas de raciocínio reside na motivação para transformar o mundo natural. Para Foster (2002), o design atua como um modulador cultural pró capitalismo, e para Flusser (2007), a atuação do design extrapola (mas não exclui) a dimensão estética apontada por Foster (2002).

Estas considerações explicam em parte porque a palavra design ocupa o espaço que lhe é conferido no discurso contemporâneo, ora trabalhando em prol do modelo de expansão, sugerido por Margolin (1996) com foco no indivíduo, apontado por Bauman (2001); ora agindo a favor do modelo de equilíbrio com foco no cidadão. No entanto, ainda sem respostas conclusivas para as questões inicialmente colocadas neste trabalho sobre a posição assumida pelo design frente ao cenário complexo e paradoxal da contemporaneidade, julga-se relevante a reflexão sobre um conceito fundamental para este debate, 
o de identidade. O objetivo é direcionar a discussão para o que Foster (2002) chama de poder devastador do design e a sua relação com a crise cultural apesentada pelo autor.

\section{As bases da crise cultural e a dimensão de valor}

O exemplo trazido por Foster (2002) em Design and Crime das massas de pessoas projetadas pelo design e a sua relação com a revista The New Yorker no contexto norte americano, referindo-se à existência de uma elite social que se confunde com uma elite cultural (uma espécie de vulgarização do valor na megastore, onde a fantasia da suspensão das divisões de classe é ofertada), nos remete diretamente aos conceitos de identidade, imagem, representação e valor.

No livro As identidades Assassinas, Amim Maalouf (2009) defende a existência de um ponto essencial quando nos debruçamos sobre a noção de identidade tal como ela se apresenta nos nossos dias: a existência de um fosso entre o que somos e o que acreditamos ser. Segundo o autor, a identidade de cada pessoa é constituída por um conjunto de elementos que não se limitam aos registros oficiais. E mais, ela constrói-se e transforma-se ao longo da existência de cada pessoa diante dos estímulos diversos recebidos pelo ambiente social. Somos então desenhados? Por quem? Seria possível afirmar que a identidade é, antes de tudo, uma questão de símbolos e, mesmo, de representações?

No que se refere às representações, Michel Maffesoli (1996), sociólogo francês e teórico no campo da prevalência do imaginário nas sociedades pósmodernas, defende que, contra todas as doutrinas ascéticas, para ser, algo deve parecer. Trata-se de um dado questionável, no entanto, muitas vezes aplicável no contexto atual, e de consequências epistemológicas múltiplas.

Este ponto de vista conduz a considerar o corpo individual e social e suas diversas aparências como o pivô, em torno do qual, muitas vezes, se ordena a vida social. Assim segundo Maffesoli (1996) cada cultura é definida pela acentuação que dá às suas relações sociais, em seu exterior ou em seu interior, revelando assim uma estreita ligação com o conceito de identidade. Esta, por sua vez, é percebida graças às características representáveis - imagens - que se convertem em traços distintivos. Sob esta perspectiva é importante assinalar que as imagens referidas não necessariamente representam construções gráficas de expressão visual, e sim, quaisquer construções pelas quais se pode significar determinada experiência regular isolável da experiência fenomênica do mundo.

No primeiro capítulo de Design and Crime Hal Foster (2002) periodiza três fases da indústria no século XX: a primeira nos anos de 1920, caracterizados pela expansão do rádio; a segunda, marcada pela produção pós-guerra 
da sociedade de consumo; e uma terceira fase caracterizada pela revolução digital. Não coincidentemente estas três fases acompanham o aumento progressivo do poder de influência das imagens no comportamento humano, assim como o aumento da complexidade observado na situação paradoxal da sociedade contemporânea apontado por Margolin (1996) e Bauman (2001).

Assim, parece difícil negar que os detentores das técnicas de manipulação de imagens (ou agentes transformadores do mundo natural sob a ótica de Flusser) assumem um papel estratégico neste cenário, como defende Foster (2002).

Segundo Flusser (2007), no cenário contemporâneo a experiência do mundo passa a ser regida por códigos, convenções, linguagens e projetos capazes de reformular a percepção, muito mais do que a paisagem. Com isso, os novos meios, da maneira como funcionam hoje, podem transformar as imagens em verdadeiros modelos de comportamento a serem reproduzidos, concordando com Foster (2002). Entretanto, entende-se que se a imagem como construção mental seja o veículo máximo do simbólico. Assim, pode assumir-se a existência da relação entre a crise cultural e a forma como as imagens estão sendo construídas, veiculadas e assimiladas.

Façamos um parêntese para a metáfora de Maturana e Varela (2001, p. 11), defensores da visão sistêmica do mundo:

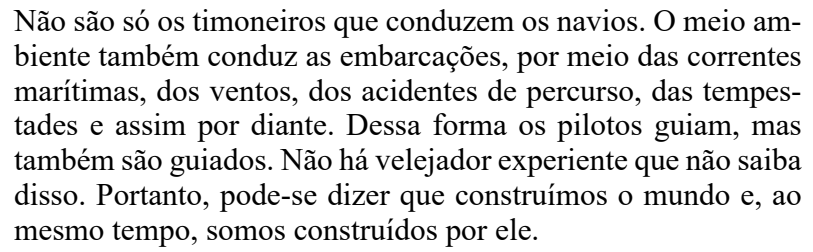

A partir deste ponto de vista, entende-se que é a noção de valor que norteia o grau de importância que as pessoas atribuem aos diferentes tipos de produto, desencadeando a crise cultural sinalizada por Foster (2002). Assim, a forma como as imagens são construídas e gerenciadas se reflete diretamente na noção de valor, uma vez que apresenta relação direta com as escolhas de cada indivíduo.

Ao constatar que muitas vezes, as pessoas consomem produtos exclusivamente com a intensão de impressionar outras pessoas (assumindo este ato também como uma necessidade), evidencia-se a existência do valor simbólico dos produtos. Este está associado ao desejo de manifestar a identidade social, pertença, posicionamento político, entre outras intenções. Em geral, esta dimensão de valor está relacionada à condição de interpretação de um produto 
em um referencial estético. Do ponto de vista do design observa-se que esta dimensão de valor é a peça chave de direcionamento para a materialização de desejos. Para serem as pessoas querem parecer, como defende Maffesoli (1996), e o fazem por meio de imagens, expressão máxima do valor simbólico.

Este raciocínio fundamenta, em parte, a teoria de Foster (2002) que aponta o design como um manipulador e agente do consumo. Como atividade profissional o design nasceu para traduzir em produtos as necessidades das pessoas, dando assim, também, resposta aos mercados, uma vez que estes produtos são comercializados (CARDOSO, 2013). Com isso, pouco mais de uma década após a publicação de Design and Crime: and other diatribes, julga-se relevante observarmos as transformações metodológicas do design como disciplina a fim de contextualizar o crime do design apontado por Foster (2002).

\section{Novos desafios à prática disciplinar do design}

Se observarmos o design como uma disciplina em linhas evolutivas, é possível não só identificar inúmeras transformações na profissão nas últimas décadas, como também, nos tempos atuais, diferentes correntes com abordagens distintas. Nesse sentido, considerando uma possível taxionomia dos campos da pesquisa de uma ciência do design, considera-se relevante compreender as mudanças nos métodos adotados por este campo do conhecimento ao longo de sua existência que contribuíram para a emergência destas diferentes correntes.

Bayazit (2004) aponta no texto Investigating design: a review of forty years of design research a existência de duas grandes gerações metodológicas de design: First Generation Design Methods e Second Generation Design Methods. A primeira geração apontada por Bayazit (2004) contemplava métodos de trabalho de caráter simplista, baseados na incorporação de técnicas e critérios científicos racionais no processo de tomada de decisões em design numa tentativa de otimizar as decisões. Os métodos de design de primeira geração foram fortemente influenciados pela objetividade e racionalidade adotadas pela escola Bauhaus, onde foram estabelecidos importantes fundamentos metodológicos para o ensino de design, mesmo após seu encerramento.

Alvo de muitas críticas, principalmente relacionadas à simplificação excessiva dos problemas, a primeira geração de métodos de design a partir da década de 1960 cede lugar ao que Bayazit (2004) aponta como métodos de design de segunda geração. Tendo como um dos principais expoentes o teórico alemão Horst Rittel, esta segunda geração é caracterizada pela introdução de novos métodos argumentativos de concepção de projeto e de identificação, onde a complexidade dos problemas é assumida e considerada. Dentro desta perspectiva, a participação do usuário nas decisões de projeto e na identifica- 
ção dos seus objetivos são as principais características desta segunda geração metodológica exposta por Bayazit (2004).

Seguindo esta linha de raciocínio, de acordo com Broadbent (2003), dentro de uma teoria de sistemas evolutivos quatro gerações metodológicas de projeto em design são reconhecidas - craft methods, design-by-drawing methods, hard systems methods (HSMs) e soft systems methods (SSMs). Segundo o mesmo autor, à medida que cada nova geração se sobrepõe a uma anterior, um sistema de metodologias de projeto mais condizente com a realidade contemporânea emerge, e nesse sentido, uma quinta geração de metodologia de projeto estaria a surgir. Assim, Broadbent (2003) sinaliza que tal desenvolvimento irá posicionar o design como um sistema de orientação evolutiva cujo papel centraliza-se cada vez mais nos assuntos humanos.

As duas primeiras gerações expostas por Broadbent (2003), craft methods e design-by-drawing methods caracterizam-se respectivamente pela ausência de consciência no processo de desenvolvimento de produtos, marcado pela intuição, e aprendizado por tentativas no primeiro caso; e pela tomada de consciência do processo de projeto, divisão do trabalho e aceleração do processo no segundo caso. Já as gerações apontadas por Broadbent (2003), como hard systems methods e soft systems methods apresentam características comuns às gerações expostas por Bayazit (2004).

Segundo Broadbent (2003), diante da complexidade dos problemas, da difusão da informação e do número crescente de envolvidos no processo de projeto, os SSMS despontam como uma proposta de métodos baseada no modelo de processo argumentativo, onde as soluções emergem gradualmente entre os envolvidos no processo. Horst Rittel mais uma vez é citado como um dos expoentes deste processo no início dos anos 1970 quando se tornou evidente que a complexidade superou a capacidade dos métodos disponíveis. Dentro desta perspectiva os SSMS são vistos como uma resposta metodológica de base centrada no pensamento sistêmico que visa promover a participação e a inclusão de crenças, pontos de vista, valores, que promovam o surgimento de novas percepções fundamentais no âmbito do design. Em particular, eles estão bem adaptados à imprecisão, aos problemas complexos, ao contrário dos HSMs.

Ainda de acordo com Broadbent (2003), os SSMs tendem a gerar uma compreensão partilhada dos problemas e a não produzir respostas definitivas aos mesmos, admitindo assim que o processo de investigação é inesgotável. Vista como uma metodologia em fase de amadurecimento, as diretrizes apontadas pelos SSMs já servem de base para uma possível quinta geração de métodos denominada por Broadbent (2003) como next generation. Segundo o autor o processo evolutivo é constante e tende a ser cada vez mais acelerado tendo em vista velocidade das mudanças nos diversos contextos da sociedade atual. 
Com isto, de acordo com as teorias de Broadbent (2003) e Bayazit (2004) entende-se que na transição para a sociedade do conhecimento, os processos de design tendem a ser cada vez mais colaborativos, envolvendo os numerosos atores sociais direta ou indiretamente relacionados ao contexto projetual. Diante dos desafios de complexidade progressiva da contemporaneidade apontados por Bauman (2001) e Margolin (1996; 2014), o design se transforma com o objetivo de dar resposta às inúmeras crises que nos cercam ${ }^{1}$.

\section{Design em paralaxe}

A palavra paralaxe (do grego parállaxis) significa mudança, sendo também definida, no âmbito da astronomia, como "a diferença entre as direções em que um astro é visto quando observado de dois pontos da Terra" (PORTO EDITORA, 2003). Outra utilização frequente do termo dá-se no campo da fotografia para explicar os desvios de enquadramento (ou erros de paralaxe). Assim, assume-se a paralaxe neste texto como o aparente deslocamento de um objeto provocado pela mudança no posicionamento do observador.

Para contextualizar este conceito no âmbito da discussão levantada por Foster (2002) acerca da influência e posicionamento do design frente à complexidade do cenário atual, apontam-se dois aspectos contraditórios no modo como o design se transforma. De um lado observa-se a acentuação do caráter midiático de suas intervenções. Sob esta perspectiva, em geral, o design assume grande visibilidade.

A caracterização do estereótipo desta abordagem do design é representada por Hal Foster (2002) pela atuação do designer Bruce Mau. Em Design and Crime não faltam críticas ao que Foster (2002) chama de Neo-Art Nouveau, ao Estilo $2000^{2}$, e à conduta de Bruce Mau quando afirma que este é um exemplo de designer cuja produção projetual ilustra os crimes do design.

Complementando o raciocínio de Foster (2002), Margolin (2014, p. 50) argumenta que "historicamente o público não vê o design como uma prática socialmente consciente", e justifica: "os designers têm vindo a criar mobiliário atrativo e outros artigos domésticos, aparelhos e transportes relativamente acessíveis, modas agradáveis, e uma abundante gama de produtos de lazer" (MARGOLIN, 2014, p. 51).

\footnotetext{
1 Para além da crise cultural apontada por Foster (2002) e da crise financeira em evidência, apontam-se os sintomas de uma crise mais ampla, com destaque para a crise ambiental, assim como os desequilíbrios e conflitos globais dentro do sistema sociopolítico.

2 Segundo Foster (2002) na concepção do Estilo 2000 ou Design Total, os objetos são tratados como minisujeitos e isto deriva do que ele define como Neo-Art Nouveau: a ambição de tornar o homem completo pela construção de imagens que destroem as qualidades humanas, fazendo referência às críticas feitas por Adolf Loos em Ornamento e Crime, de 1931, ao movimento Art Nouveau.
} 
Reconhecendo a necessidade de dar uma nova e fundamental orientação à comunidade do design, no sentido de procurar atingir objetivos sociais latentes, Peter Butenschon, então presidente do Conselho Internacional das Organizações de Design Industrial (ICSID), fala sobre os novos objetivos para os designers em seu discurso na conferência Common Ground, realizada na Universidade de Brunel, em setembro de 2012³:

\begin{abstract}
Somos bons a desenhar frigoríficos que nos dizem quando algum artigo está em falta, mas já não somos tão bons quando se trata de arrefecer alimentos, utilizando a energia solar. As soluções estão provavelmente ao virar da esquina, mas a motivação para as pôr em prática não se encontra realmente presente, já que todos os incentivos parecem estar, por demais, intimamente ligados a um sistema de produção e consumo (MARGOLIN, 2014, p. 53).
\end{abstract}

Assim, ao contrário do que Foster (2002) defende, existe uma parcela significativa de pessoas internas à comunidade do design cientes da complexidade dos desafios a serem enfrentados. Entretanto é significativo observar a posição do presidente de uma das maiores organizações internacionais de design a reivindicar novos caminhos para o design no mesmo ano em que Hal Foster publica a obra Design and Crime.

Diante deste quadro, considera-se importante destacar que esta não é uma discussão nova no campo do design. Já no início dos anos setenta o designer Victor Papanek evidenciava a necessidade de o design voltar-se aos problemas complexos e urgentes da sociedade em Design for the Real World, dando destaque para uma crise ambiental anunciada, aos conflitos raciais e políticos. No livro, Papanek (1971), assim como Foster (2002), critica a ausência de valores humanos do Le style international, e a perversão da estética e da utilidade da casa como machine à habiter (máquina de morar), de Le Corbusier.

Nesse sentido, ainda sobre as transformações no design aponta-se uma segunda linha evolutiva da atividade que segue a transformação dos métodos de design apontados por Broadbent (2003) e Bayazit (2004). Esta adota uma visão sistêmica que se confronta com a complexidade das redes sociais à medida que desenvolve uma maior capacidade de escuta e conexão, e que atua dentro dos fenômenos da criatividade e do empreendedorismo difusos que caracterizam a sociedade atual. Sob esta perspectiva o design torna-se parte ativa nos processos de transformação diante da complexidade dos desafios. Dentro desta abordagem a preocupação obsessiva com a imagem dá lugar à

3 Peter Butenschon, 'Worlds Apart: An International Agenda for Design', palestra realizada na Common Ground, uma conferência internacional organizada pela Design Research Society na Universidade de Brunel, Inglaterra, de 5 a 8 de setembro de 2002 . 
noção estratégica e de bem-estar. Isto quer dizer, produzir artefatos que sejam ao mesmo tempo apreciados pelos potencias usuários considerando suas funções estéticas, simbólicas e práticas e capazes de regenerar a qualidade do contexto onde se encontram (MERONI, 2008).

De fato, esta ideia de design ainda é pouco difundida e compreendida na sua potencialidade. Acredita-se que em parte, esta situação deva-se ao fato de o design, sob esta perspectiva, ser visto como uma atividade complexa e relativamente recente. Ezio Manzini (2010, p. XI), um dos grandes promotores desta corrente de design, argumenta:

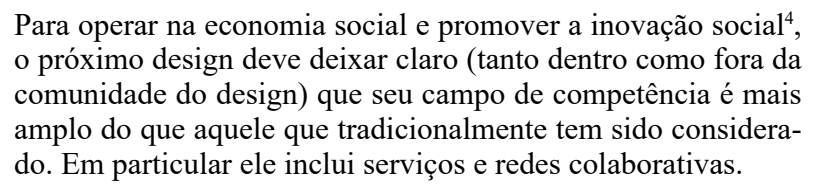

Mais precisamente, aponta Manzini (2010), para a promoção da inovação social, é necessário um movimento duplo no âmbito do design: (1) reconceituar o design, movendo (principalmente) da cultura e prática do design orientado pelo produto, para orientado pelo serviço; (2) reconceitualizar serviços, estendendo o conceito de serviço, ou melhor, de serviços padronizados para serviços colaborativos.

Assumindo como legítimos os diferentes direcionamentos do design referenciados, reforça-se a possibilidade de coexistência de diferentes correntes de design por meio das tendências de enfoque do design apontadas por Guy Bonsiepe (2013, p. 67-68):

1. design socialmente responsável, ou facilitador da vida quotidiana nos mais diversos campos: trabalho, transporte, habitação, educação, saúde e lazer;

2. design ecológico;

3. life-style design, que ocupa boa parte das exposições de design, dos festivais de design e dos comentários na mídia;

4. design de autor, com produtos assinados pelos designers famosos e geralmente destinados a uma pequena elite;

5. design-arte, ou design transdisciplinar, presente nas galerias de arte, com ênfase na estética;

6. design artesanal, que procura resgatar os materiais e as culturas locais;

$4 \quad$ Onde a inovação social é entendida como a inovação conduzida pelos esforços de grupos amplos e flexíveis de agentes sociais que criam e desenvolvem colaborativamente soluções sustentáveis. 
7. design estratégico, que apresenta uma visão ampliada do design, não se restringindo ao projeto de um objeto específico, mas incluindo-o na estratégia de negócios da empresa;

8. pesquisa em design, que procura gerar e sistematizar novos conhecimentos relevantes para a prática e a interpretação do design;

9. design experimental com novas tecnologias, sobretudo baseadas em ferramentas digitais.

Assim, propõem-se a adoção do conceito 'design em paralaxe' para explicar, em parte, as grandes diferenças de caracterização do design. Sob este raciocínio, o design é entendido como o objeto observado, e seu aparente deslocamento é provocado pela mudança no posicionamento do observador. Ou seja, na ausência de uma única definição do que seja design, e das diferentes correntes de design observadas, o posicionamento (ou o repertório) do observador é fator determinante para a construção de estereótipos.

Entende-se que quando Foster (2002) afirma que o design é um agente primordial que nos conduz ao sistema quase absoluto do consumismo contemporâneo, refere-se a um estereótipo, definido por Lippmann (1961) como imagens mentais generalizadas ou categorizadas que se interpõem, sob a forma de enviesamento, entre o indivíduo e a realidade. Para Frayling (1993), esta categoria de designer é representada de forma caricata por um jovem visionário especialista em imagem e obcecado pela aparência, estilos e tendências.

Entretanto, reforçando a existência da paralaxe do design, Tim Brown (2010), CEO e presidente da empresa norte americana de inovação e design IDEO, defende que o design não se limita a criar objetos elegantes ou embelezar o mundo. Os melhores designers, segundo ele, compatibilizam a exigência com a utilidade, as restrições com as possibilidades e as necessidades com a demanda. É o que ele chama de design com "d" minúsculo.

\section{Considerações finais}

De forma simplificada, este debate evidencia os desafios enfrentados na atualidade pelo design com destaque para as questões relacionadas com valores e ética. Os conflitos entre indivíduo e cidadão (BAUMAN, 2001) e modelo de expansão e modelo de equilíbrio (MARGOLIN, 1996) ilustram a situação paradoxal enfrentada pelo design atualmente como campo de atuação.

Assim, admitindo a existência de múltiplas correntes de design e extrapolando a questão da paralaxe do design, os desafios concretos da teoria e prática do design (na fenomenologia, na praxiologia e na epistemologia) voltam-se 
para a dificuldade de condução de um tipo de inovação pautada no princípio da evolução dos sistemas. Neste contexto destacam-se as seguintes ambições: integrar redes colaborativas, promover modelos de interação (CELASCHI; CELI; GARCÍA, 2011; MORAES, 2010), reconhecer, conectar valores, e convertê-los em atributos mensuráveis de forma sustentável (MANZINI, 2010; MERONI, 2008).

Segundo Margolin (2014, p.18), para que o design oriente suas ações de modulação para fins sociais, contrariando a visão de Foster (2002), “qualquer convocatória aos designers deverá ter em conta a questão da autonomia, ou a capacidade destes para definir os seus próprios objetivos" (partindo do pressuposto que são outras pessoas que geralmente definem as condições de trabalho dos designers). Assim, a superação da falta de autonomia para a criação coletiva de visões de futuro mais humanas e éticas em um mundo cada vez mais polarizado caracteriza-se como outro grande desafio imposto ao design. Além disso, observando as observações de Foster (2002), aparentemente o crime do design reside, na maioria das vezes, na cumplicidade no processo de transformação do mundo natural, mas não na autoria plena deste.

Podemos então assumir a existência do crime de design indicado por Foster (2002)?

Concordando com Margolin (2014) que os designers devem responsabilizar-se, ao menos parcialmente, pela não elevação do bem-estar da humanidade no contexto da criação de produtos e serviços, entende-se como legítimas as críticas de Foster (2002) à conduta do design como campo disciplinar. Entretanto, defende-se que a visão do crítico é parcial e retrata apenas um fragmento do design como campo de atuação, excluindo tantas outras possibilidades de atuação anteriormente apontadas ao longo do texto.

De fato, num contexto histórico, a missão do designer já foi mais simples do que é hoje, e a sua responsabilidade, mais fácil de definir. Entretanto questiona-se: na era da transdisciplinaridade ${ }^{5}$, da abordagem sistêmica de problemas, cabe ainda apontarmos culpados para os problemas da coletividade?

Maturana e Varela (2001) falam sobre a necessidade de assunção de responsabilidades, e este é sem dúvida um desafio à todas as áreas do conhecimento, incluindo o design. A crise cultural revela a condição de manipulador e manipulado do homem contemporâneo, mostrando que o design apontado por Foster (2002) não é exclusividade de designers. Esse ponto de vista, configura-se não como uma defesa em favor do design, mas sim como um convite à participação ativa na construção de cenários melhores. Mais ainda, é um convite à assunção de responsabilidades que ele implica.

$5 \quad$ A transdisciplinaridade, diz respeito àquilo que está ao mesmo tempo entre as disciplinas, através das diferentes disciplinas e além de qualquer disciplina (NICOLESCU, 2000). 
As transformações metodológicas apontadas por Broadbent (2003) e Bayazit (2004) mostram que mudanças de direcionamento já foram iniciadas no campo do design, provocando uma gradual aproximação do design às abordagens colaborativas. Dentro deste entendimento, a inovação operada pelo design não necessariamente posiciona-se dentro do modelo de expansão exposto por Margolin (1996), podendo ser administrada de acordo com diferentes interesses. $\mathrm{O}$ mesmo ocorre com o design, o que pode ser constatado nas tendências de enfoque apontadas por Bonsiepe (2013), algumas das quais coincidem com o estereótipo do design apresentado por Foster (2002).

Por fim, é interessante observar que a principal missão do designer segundo Owen Jones, autor do clássico The Grammar of Ornament, publicado no século XIX, era "decorar ou dar forma a produtos" (MARGOLIN, 2014, p. 29), coincide com a visão de Foster sobre o design no ano 2002 em Design and Crime. Isso mostra que o design, assumido neste trabalho como um campo de atuação multifacetado, com contornos pouco nítidos, e por natureza flexível (uma vez que acompanha as oscilações do corpo social), tem um grande desafio para além dos paradoxos apontados: lidar com a sua multiplicidade de corpos que o faz objeto de paralaxe.

\section{Referências}

BAUMAN, Zygmunt. Modernidade líquida. Rio de Janeiro: Zahar, 2001.

BAYAZIT, Nigan. Investigating Design: A Review of Forty Years of Design Research. Design Issues, v. 20, n. 1, p.16-29, winter, 2004.

BONSIEPE, Guy. Tendências e antitendências no design industrial. In: MORAES, Dijon; CELASCHI, Flaviano (Orgs.). Caderno de estudos avançados em design: design e humanismo. Barbacena: EdUEMG, 2013. p. 61-69. (Vol. 7).

BROADBEnT, John. Generations in Design Methodology. The Design Journal, v. 6, n. 1, p. 2-13, March, 2003.

BROWN, Tim. Design Thinking: uma metodologia poderosa para decretar o fim de velhas ideias. Rio de Janeiro: Elsevier, 2010.

CARDOSO, Rafael. Design para um mundo complexo. São Paulo: Cosac Naify, 2013.

CELASCHI, Flaviano; CELI, Manuela; GARCÍA, Laura Mata. The Extended Value of Design: An Advanced Design Perspective. Design Management Journal, v. 6, n. 1, p. 6-15, October. 2011.

CERTEAU, Michel de. A invenção do cotidiano: artes de fazer. Petrópolis: Vozes, 1994.

FLUSSER, Vilém. O mundo codificado: por uma filosofia do design e da comunicação. São 
WIELEWICKI, Patrícia, RODA Rui Miguel Ferreira. Design em paralaxe: uma discussão sobre a...

Paulo: Cosac Naify, 2007.

FOSTER, Hal. Design and Crime: and other diatribes. London: Verso, 2002.

FRAYLING, Christopher. Research in Art and Design. Research Papers: Royal College of Art, v. 1, n.1, p. 1-5. 1993/1994.

LIPPMANN, W. Public Opinion. New York: Free Press, 1961.

MAALOUF, Amin. As Identidades assassinas. Lisboa: Difel, 2009.

MAFFESOLI, Michel. No fundo das aparências. Petrópolis: Vozes, 1996.

MANZINI, Ezio. Metaprojeto hoje: guia para uma fase de transição. In: MORAES, Dijon de. Metaprojeto: o design do design. São Paulo: Blucher, 2010.

MARGOLIN, Victor. Global Expansion or Global Equilibrium? Design and the World Situation. Design Issues, v. 12, n. 2, p. 22-32, Summer, 1996. 2014.

Design e risco de mudança. Vila do Conde / Matosinhos: Verso da História / ESAD,

MATURANA, Humberto; VARELA, Francisco. A árvore do conhecimento: as bases biológicas da compreensão humana. São Paulo: Palas Athena, 2001.

MERONI, Anna. Strategic design: where are we now? Reflection around the foundations of a recent discipline. Strategic Design Research Journal, v.1, p. 31-38, July/Dec. 2008.

MORAES, Dijon de. Metaprojeto: o design do design. São Paulo: Edgard Blucher, 2010.

NICOLESCU, Basarab. O Manifesto da Transdisciplinaridade. Lisboa: Hugin, 2000.

PAPANEK, Victor. Design for the Real World: Human Ecology and Social Change. New York: Pantheon Books, 1971.

PORTO EDITORA (Portugal). Dicionário da Língua Portuguesa com Acordo Ortográfico. Porto: Porto Editora, 2003. Disponível em: $<$ http://www.infopedia.pt/dicionarios/lingua-portuguesa/paralaxe $>$. Acesso em: 17 jul. 2015.

\section{Agradecimentos}

Os autores agradecem ao Conselho Nacional de Desenvolvimento Científico e Tecnológico (CNPq), que por meio do Programa Ciências sem Fronteiras do governo federal brasileiro, apoiou financeiramente este trabalho.

Patrícia Feronha Wielewicki é PhD persquisador em Arte e Design na Universidade do Porto, Portugal desde 2013. Mestre em Design pela Universidade do Aveiro, Portugal. Integra redes de investigação na Universidade do Porto e na Universidade 
de Aveiro, Portugal executando diversos processos criativos visando o desenvolvimento de estratégias de inovação baseadas no Design Estratégico. Pesquisadora do Conselho Nacional de Desenvolvimento Científico e Tecnológico (CNPq) realizou pesquisas nas Áreas de inovação e projetos em Design. E-mail:patriciafw@gmail.com

Rui Miguel Ferreira Roda é professor e pesquisador em Design do Politécnico de Milão - Itália. PhD in Design pelo Politécnico de Milão (2007). Membro da Associação Portuguesa de Arquitetura. Participa em projetos de desenvolvimento em várias empresas de design (e.g. Sottsass Associati) e redes de investigação nas referidas instituições. E-mail: rui.roda@me.com 